\title{
PROGRAMA NACIONAL DE CAPACITAÇÃO DE CONSELHEIROS MUNICIPAIS DE EDUCAÇÃO NO ESTADO DO RIO GRANDE DO SUL: IMPACTOS E PERSPECTIVAS À GESTÃO EDUCACIONAL
}

http://dx.doi.org/10.5902/2318133820467

\author{
Marilene Gabriel Dalla Corte \\ Andrelisa Goulart de Mello \\ Marina Lara Silva dos Santos Teixeira \\ Francine Mendonça da Silva \\ Universidade Federal de Santa Maria, Brasil.
}

Resumo

Este texto relaciona-se ao Programa Nacional de Capacitação de Conselheiros Municipais de Educação - Pró-Conselho -, considerado uma das ações de consecução da política de democratização da gestão educacional no Brasil. Analisa-se os impactos e as perspectivas da formação continuada desenvolvida pelo Pró-Conselho, relacionadas com a atuação dos conselheiros municipais de educação na Região da Amcentro/RS. Como principais resultados identificou-se o fortalecimento dos conselhos municipais de educação como instâncias de sistema de ensino, tendo por base a reflexão acerca dos fundamentos das políticas públicas e gestão educacional; reativação ou rearticulação de conselhos de educação já existentes; criação de sistemas municipais de ensino; fortalecimento de rede compartilhada virtual na gestão educacional municipal. Tais impactos e perspectivas reverberam na necessária compreensão e na realização de um trabalho educativo coletivo e compartilhado que considera que as políticas públicas educacionais precisam ser delineadas, articuladas e implantadas na lógica da qualificação e interdependência na gestão educacional municipal.

Palavras-chave: conselho municipal de educação, formação continuada, políticas públicas, gestão educacional.

\section{NATIONAL TRAINING PROGRAM OF MUNICIPAL EDUCATION COUNCILLORS IN AMCENTRO/RS: IMPACTS AND PERSPECTIVES TO THE MANAGEMENT EDUCATION}

\begin{abstract}
This production is related to the National Training of Municipal Education Councillors Program Pró-Conselho -, considering one of the actions about democratization policy of education management in Brazil. The impacts and prospects of continuing education developed by PróConselho were analyzed and also the performance of municipal education councilors in the region Amcentro - RS. As main result, was identified the strengthening of Municipal Education Councils like Education System organ, having as base the reflection on the fundamentals of public policy and educational management; [re] activation or [re] articulation of Education Councils already existed; the creation of Municipal Education Systems; strengthening of virtual shared network in the municipal educational administration. The impacts and perspectives reverberate in the required understanding and the realization of a collective educational work and which considers that the
\end{abstract}

\begin{tabular}{|l|l|l|l|l|l}
\hline Regae: Rev. Gest. Aval. Educ. & Santa Maria & v. 5 & n. 9 & Jan./jun. 2016 & p. $75-92$ \\
\hline
\end{tabular} 
educational policies need to be defined, articulated and implemented in the logic of qualification and interdependence in the municipal educational administration.

Key-words: municipal education council, continuing training, public policy, educational management. 


\section{Considerações iniciais}

este texto abordam-se os impactos e as perspectivas da formação continuada de conselheiros municipais de educação no Estado do Rio

1 Grande do Sul, tendo por base os preceitos do Programa Nacional de Capacitação de Conselheiros Municipais de Educação - Pró-Conselho - no Brasil.

O Pró-Conselho ${ }^{1}$ é um programa da Secretaria da Educação Básica do Ministério da Educação que tem em seus princípios fundantes o desenvolvimento da política de democratização da gestão educacional no país. É realizado em regime de parceria com instituições federais de ensino superior, Fórum Nacional dos Conselhos Estaduais de Educação, União Nacional de Conselhos Municipais de Educação, União Nacional dos Dirigentes Municipais de Educação, entre outros. O Curso de Formação Continuada de Conselheiros Municiais de Educação, na modalidade a distância, é uma das ações do Pró-Conselho nacional e objetiva qualificar a atuação do conselheiro ou técnico com relação às ações educativas, à legislação e aos mecanismos de financiamento, repasse e controle do uso das verbas da educação, de modo a tornar os conselhos municipais de educação atuantes em suas instâncias sócio-educacionais.

Além de constituir um projeto de extensão voltado para a formação continuada, o Pró-Conselho desenvolvido pela UFSM constitui-se lócus de pesquisa do Observatório de Educação Interlocuções entre políticas públicas e ações pedagógicas: limites e possibilidades, da Coordenação de Aperfeiçoamento de Pessoal de Nível Superior, vinculado a um grupo de pesquisa do Centro de Educação da Universidade Federal de Santa Maria. As discussões que se inserem neste Observatório objetivam identificar e analisar os limites e as possibilidades das ações pedagógicas no contexto da gestão educacional a partir dos impactos e desafios enfrentados pelos sistemas e interferência das políticas públicas educacionais nas reformas educacionais a partir do processo de interlocução entre educação básica e superior.

Nesse sentido, este texto dá visibilidade aos estudos e banco de dados que atendem ao um dos objetivos específicos do Observatório: delinear e analisar os limites e as possibilidades dos conselhos municipais de educação, vinculados ao Pró-Conselho na região de abrangência da Associação dos Municípios do Centro do Estado do Rio Grande do Sul - Amcentro/RS -, considerando a existência de sistema, configuração dos CMEs, proposições de políticas públicas, ações desenvolvidas junto as mantenedoras e escolas públicas, orientações para a elaboração dos projetos político-pedagógicos das escolas públicas, formação dos conselheiros entre outros aspectos subjacentes ao perfil e atuação dos conselheiros. Neste caso, entre as categorias de análise do Observatório, volta-se para o estudo específico acerca da formação e atuação dos conselheiros municipais de educação. Para tanto, objetiva-se analisar os impactos e as perspectivas da formação continuada desenvolvida no âmbito da segunda edição Pró-Conselho/UFSM à atuação dos conselheiros junto aos conselhos municipais de educação na região de abrangência da Amcentro/RS.

1 O Pró-Conselho foi instituído pela Secretaria de Educação Básica do Ministério da Educação por meio da Portaria Ministerial no 3.272/2003.

Regae: Rev. Gest. Aval. Educ. Santa Maria v. 5 ก. 9 Jan./jun. 2016 p. $75-92$ 


\section{Aspectos metodológicos}

O delineamento metodológico desta pesquisa subsidia-se na metodologia quantiqualitativa (Trivinos, 2008; Minayo, 2004) e no estudo de caso (Yin, 2005), os quais se constituem como modalidade do fazer investigativo, delimitando o contexto, tornando-o representativo de uma realidade e práticas subjacentes ao Pró-Conselho no Estado do Rio Grande do Sul.

A metodologia qualitativa, tendo por base os preceitos de Minayo (2004), "busca apreender a prática social empírica dos indivíduos em sociedade e realizar a crítica das ideologias, isto é, do imbricamento do sujeito e do objeto, ambos históricos comprometidos com os interesses e as lutas sociais de seu tempo" (p. 65). Para Trivinos (2008, p. 67), "o quantitativo é característico dos fenômenos sociais também. [...] A quantidade e a qualidade estão unidas e são interdependentes. [...] a mudança de qualidade depende, em determinado momento, da mudança de quantidade". Assim sendo, a metodologia quanti-qualitativa, como abordagem de investigação, está tecnicamente subsidiada pelo estudo de caso analítico que, segundo Yin (2005), pode proporcionar significativo avanço no conhecimento do contexto e esse tipo de investigação é elementar à descrição e à análise de dados os quais não se tem controle específico acerca das causas e consequências comportamentais ou institucionais.

No que diz respeito aos processos de coleta de dados pesquisa utilizou-se informações oriundas de questionário online produzido e disponibilizado aos cursistas junto ao ambiente ${ }^{2}$ virtual do Curso de Formação Continuada de Conselheiros Municipais de Educação, o qual é realizado na modalidade a distância, com duração de seis meses cada edição do curso, com carga horária total de 180 horas: 164h a distância e $16 \mathrm{~h}$ presenciais. Considerando esses aspectos que circundam a abordagem de pesquisa e a análise inter-relacionam-se os contextos dos conselhos municipais de educação aos sistemas municipais de ensino na região de abrangência da Associação dos Municípios do Centro do Estado do Rio Grande do Sul.

As técnicas utilizadas para a construção dos dados (Gil, 2004) pautaram-se no questionário misto online aplicado aos municípios participantes do curso, considerando os discursos dos conselheiros matriculados acerca dos impactos do curso à sua formação e atuação na gestão educacional municipal. Utilizou-se indicadores do Instituto Nacional de Estudos e Pesquisa Educacionais. É importante esclarecer que dos 33 municípios integrantes da Região Amcentro/RS, um total de 27 já participaram do Pró-Conselho/RS e apenas 17 possuem sistema municipal de ensino. Na $2^{2}$ edição do curso, em 2014, participaram os conselheiros de 15 municípios, sendo que nove possuem SME e seis não possuem. Assim sendo, esta análise de dados está relacionada aos municípios partícipes da $2^{2}$ edição do curso, partindo do pressuposto da necessária autonomia para propor e gestar políticas públicas educacionais e que, em tese, os municípios que já constituíram SME se empoderam das funções normativa, deliberativa e de controle social, via conselho de educação, que são essenciais para os processos de democratização da gestão educacional; já os que não possuem SME precisam investir na conquista tais espaços de gestão das políticas públicas em âmbito municipal, uma vez que o CME fica com sua atuação restrita.

${ }^{2}$ Ambiente Moodle Conselheiros, disponível em <http://ccmers.proj.ufsm.br/moodle3/>.

\begin{tabular}{|l|c|c|c|c|}
\hline Regae: Rev. Gest. Aval. Educ. & Santa Maria & v. 5 & n. 9 & Jan./jun. 2016
\end{tabular} 
Tendo por base a concepção de que a análise de conteúdo acontece, sobretudo, a partir do fato de que todo o conteúdo tem significado, utiliza-se do paradigma interpretativo que pode contribuir para verificar o que os pesquisados pensam sobre determinadas questões e no que isso interfere na sua função, na atuação social e profissional. Para Bogdan e Bikklen (1994) a análise de conteúdo está ancorada num paradigma interpretativo e, sobretudo, pressupõe a definição clara do que se quer analisar e do que se entende por cada unidade de análise em suas concepções e ações, fins, meios, condições e contexto, em que não se pode perder de vista que são vários os fatores que influenciam a maneira como as pessoas e instituições se organizam, se relacionam, interpretam e intervém no contexto em que vivem.

\section{Os conselhos municipais de educação nos processos de democratização da gestão educacional e a formação continuada de conselheiros}

Considerando trajetória das políticas públicas no Brasil avançou-se para a reorganização democrática dos processos de gestão educacional e escolar e, nesse sentido, ampliou-se a necessidade de implantação e interferência de programas potencializadores de formação continuada dos sujeitos que atuam em tais instâncias. Tais processos formativos estão inter-relacionados aos aspectos organizativos da sociedade e do sistema educacional e respectivas redes/instituições escolares e ancoram-se em marcos legais, como a Constituição Federal de 1988, a Lei de Diretrizes e Bases da Educação Nacional e o Plano Nacional de Educação, entre outros. Nessa lógica, Frigotto (2001, p. 641) define que tais políticas públicas surgem como forma de "regulação social e ajuste estrutural, como um mecanismo formal (Estado) e informal (sociedade civil) que estruturam o conjunto de setores da vida social, política e econômica, nas dimensões públicas e privada". Conforme Telles (2001), a partir da LDBN/96, os CME passaram a caracterizar-se de outra maneira, considerando um novo formato de relacionamento entre Estado e sociedade.

Esses marcos regulatórios, subjacentes às políticas públicas para a educação no país, destacam a necessária compreensão e consecução de processos de gestão democrática nos sistemas de ensino e respectivos órgãos e instituições de educativas. Assim sendo, busca-se a superação do conceito de administração na perspectiva tecnocrata, não sendo mais possível um "antigo enfoque da administração científica, pelo qual se considera que, tanto a organização como as pessoas que nela atuam, são componentes de uma máquina controlada de fora para dentro e de cima para baixo" (Lück, 2007, p. 50). Para tanto, a Constituição de 1988 normatiza a democratização do ensino e a descentralização de poderes aos entes federados, entre eles o município, antes submetido estreitamente às decisões de âmbito federal e estadual, sendo que os municípios passam por ressignificação e reconstrução dos seus processos de gestão educacional e escolar, na perspectiva de constituir ou consolidar seus sistemas municipais de ensino e respectivos conselhos municipais de educação.

Os conselhos municipais de educação, no contexto da gestão educacional, passaram a ser considerados instâncias colegiadas normativas, consultivas, deliberativas, fiscalizadoras, com funções e atribuições relativas à condução da educação democrática. Tais órgãos colegiados pressupõem uma gestão compartilhada nos processos de planejamento, execução e avaliação educacional e, dessa maneira, se passou a requerer 
uma nova configuração na natureza dos conselhos de educação: "a passagem de órgãos técnicos de governo para o exercício de funções de Estado" (Bordignon, 2008, p. 14), representando a diversidade social e articulando uma ponte entre a sociedade e 0 governo.

Em sentido geral, os conselhos de educação, enquanto agrupamentos de pessoas que deliberam sobre aspectos políticos e pedagógicos nas instâncias nacional, estadual e municipal, precisam se constituir em instâncias coletivas de tomada de decisões (Lück, 2006). Porém, a abertura de espaços públicos e de participação da sociedade civil requer reconstrução do conhecimento e o empoderamento dos sujeitos que constituem tais instâncias colegiadas na ótica de qualificação dos mecanismos de democratização da sociedade. Para tanto, a formação continuada de conselheiros e técnicos de secretarias amplia o fortalecimento a atuação desses contextos, permeados pela qualidade de atuação desses sujeitos que realizam a leitura, análise e proposição de políticas públicas educacionais.

A formação continuada de conselheiros municipais de educação requer reflexão sobre seus contextos de atuação, o que pressupõe investimento na formação de sujeitos capazes de reconhecer os processos formativos dos quais participam, mas, sobretudo, que tais processos ampliem sua capacidade de análise e posicionamento acerca das políticas públicas e aspectos subjacentes à gestão educacional e escolar, contribuindo, portanto, com possibilidades de transformação da realidade educacional no âmbito municipal como membros de um determinado grupo social ou profissional. Libâneo, Oliveira e Toschi (2005), defendem a necessária atuação de pessoas qualificadas, politizadas e comprometidas para atuarem na dinâmica das políticas educacionais.

Parte-se do pressuposto de que a formação continuada constitui-se investimento para a transformação no exercício da profissão (Gómez, 1997), destacando a necessária atuação proativa e responsável do conselheiro de educação em seu grupo de pares, como também a representatividade deste grupo na construção cotidiana de uma nova cultura no contexto da democratização da gestão da educação municipal. Nessa ótica, participar de processos formativos na construção de conhecimento requer a reconstrução de saberes subjacentes ao exercício da sua função, os quais contribuem para o desenvolvimento da inovação político-pedagógica fundamentada em conhecimentos teóricos e legais diretamente interligados ao cotidiano das práticas de gestão educacional e escolar. Pressupõe, portanto, a formação de um sujeito capaz de compreender e implementar os processos formativos dos quais participa e de reconhecer-se como sujeito representativo e atuante num grupo, instituição e/ou órgão educacional.

\section{Pró-Conselho no Rio Grande do Sul e a formação continuada na Região Amcentro/RS}

No Rio Grande do Sul o Pró-conselho é realizado em parceria com a UFSM. Já foram desenvolvidas duas edições do curso no RS e a $3^{\text {a }}$ edição está em andamento. A $1^{\text {a }}$ edição do curso foi executada em 2013 com a meta de capacitar 120 cursistas. A $2^{\mathrm{a}}$ edição foi executada em duas ofertas nos anos de 2013 e 2014 com a meta capacitar 320 cursistas - conselheiros municipais de educação e técnicos das secretarias municipais de educação -; a $3^{\text {a }}$ edição, em desenvolvimento, tem a meta de capacitar 180 cursistas. $O$ curso é constituído pela reconstrução de conhecimentos, pelo compartilhamento saberes 
e fazeres entre professores/tutores/cursistas e cursistas/cursistas, entre outros, criando um espaço de aprendizagem mútua, no contexto da sociedade em rede, que se configura nas relações que as pessoas têm no cenário da sociedade atual.

Para Castells (2005, p. 566). "uma estrutura social com base em redes é um sistema aberto altamente dinâmico suscetível de inovação sem ameaças ao seu equilíbrio", então a dinâmica do acesso à informação e comunicação amplia-se significativamente, tornando as relações de produção do conhecimento, tanto no âmbito pessoal, quanto profissional, mais atrativas, interativas e desafiadoras. Essa perspectiva repercute, especialmente, nas potencialidades de interlocução com diversas áreas, setores, órgãos e instituições em íntima aproximação e reflexão acerca das interfaces da atuação profissional; requer formação continuada para que os sujeitos sociais estejam capacitados e atualizados no que diz respeito aos mecanismos tecnológicos, bem como às informações e ao conhecimento que são produzidos em tempo real e cada vez mais rápido na sociedade em rede, ou seja, estamos em constante transformação.

Ao mapear a conjuntura dos dados produzidos no Observatório de Educação com base nos indicadores do Inep, buscou-se identificar dados que dizem respeito ao número de alunos matriculados na educação básica no Brasil em 2014, que contabilizou 49.771.371, sendo que as redes municipais foram as responsáveis por mais da metade das matrículas constituindo um total de 23.089 .488 alunos (Inep, 2014). Diante dos indicadores de matrícula do país em sua totalidade e, também, instâncias municipais, compreende-se a complexidade e o desafio que circunscreve a gestão administrativa, financeira e pedagógica, sobretudo aos municípios. Daí a relevância da interdependência e cooperação técnica nos processos de gestão educacional a partir de uma visão sistêmica pelos sujeitos envolvidos em tais instâncias de gestão. Nessa ótica, quando se analisa os indicadores do Instituto por regiões, verifica-se que a região Sul foi responsável, em 2014, por 6.472 .982 alunos matriculados na educação básica (Inep, 2014).

No que tange ao Estado do Rio Grande do Sul constata-se o indicador de 930.394 alunos matriculados em 497 municípios (Inep, 2014). Na Amcentro/RS, referente aos 33 municípios da região Central do RS, conforme o que segue na tabela 1, verifica-se a distribuição de matrículas dos 17 municípios que possuem sistema municipal de ensino*.

Tabela 1 -

Distribuição de matrículas dos 17 municípios com SME na Amcentro/RS.

\begin{tabular}{|c|c|c|c|c|}
\hline \multirow[t]{2}{*}{ Município } & \multicolumn{3}{|c|}{ Matrículas 2014} & \multirow[t]{2}{*}{ Total } \\
\hline & Municipal & Estadual & Privada & \\
\hline Agudo & 1.658 & 972 & 120 & 2.750 \\
\hline Cachoeira do Sul $^{\star}$ & 4.946 & 7.348 & 2.731 & 15.025 \\
\hline Capão do Cipó & 352 & 237 & 0 & 589 \\
\hline Dilermando de Aguiar* & 257 & 250 & 0 & 507 \\
\hline Faxinal do Soturno & 367 & 728 & 0 & 1.095 \\
\hline Formigueiro* & 591 & 646 & 0 & 1.237 \\
\hline Itaara & 692 & 186 & 24 & 902 \\
\hline Mata* $^{*}$ & 441 & 432 & 0 & 873 \\
\hline Regae: Rev. Gest. Aval. Educ. & Santa Maria & & Jan./jun. & p. $75-92$ \\
\hline
\end{tabular}




\begin{tabular}{l|c|c|c|c}
\hline Nova Esperança do Sul $^{*}$ & 469 & 460 & 0 & 929 \\
\hline Paraíso do Sul & 541 & 481 & 0 & 1.022 \\
\hline Restinga Seca* & 1.288 & 1.195 & 59 & 2.542 \\
\hline Santa Maria* & 16.028 & 18.010 & 12.346 & 46.384 \\
\hline Santiago & 3.506 & 4.358 & 1.305 & 9.169 \\
\hline São Francisco de Assis & 1.592 & 1.486 & 0 & 3.078 \\
\hline São Sepé* & 1.730 & 1.815 & 332 & 3.877 \\
\hline São Vicente do Sul & 762 & 825 & 0 & 1.587 \\
\hline Tupanciretã & 2.293 & 2.207 & 329 & 4.829 \\
\hline Total & 37.513 & 41.636 & 17.246 & 93.395 \\
\hline
\end{tabular}

Fonte: Inep (2014).

Analisando o quantitativo de matrículas nas redes escolares dos referidos municípios, se consegue dimensionar a importância do planejamento em suas políticas públicas e processos de gestão. Isso significa que os gestores municipais necessitam participar, por exemplo, de processos de elaboração do plano municipal de educação, reconhecer as principais fontes de financiamento e, nesse sentido, articular as estratégias de trabalho colaborativo e de cooperação técnica que necessitam intimamente estar embasados em dados quantitativos e qualitativos que delineiam e caracterizam tais contextos educacionais municipais. É nesse processo que a existência dos Conselhos Municipais de Educação ganha concretude e contribui para o fortalecimento da autonomia, participação e descentralização do poder.

O CME, quando ativo, requer "ser a caixa de ressonância de todas as demandas, de todos os problemas, de todas as reflexões que se produzem no município quanto à educação de seus cidadãos, de suas cidadãs e da própria comunidade" (Monlevade, 2009, p. 86). Espera-se que o CME, como órgão colegiado do SME, responsável pela normatização, proposição, deliberação, mobilização e controle social, não somente se institui, mas, também, se institucionaliza nos processos de gestão educacional municipal. Em relação à funcionalidade do $C M E$ e de seus conselheiros explicita-se duas importantes questões para a atuação. Primeiramente, os sujeitos envolvidos no cotidiano de trabalho do CME necessitam considerar o conhecimento e a ação crítico-reflexiva sobre os princípios de gestão democrática e regime de colaboração.

Assim sendo, da conjuntura de 33 municípios da Amcentro/RS, 45,45\% participaram da $2^{a}$ edição do Pró-Conselho/UFSM, ou seja, nove municípios que possuem sistema de ensino e mais cinco municípios que não possuem sistema de ensino - Ivorá, Júlio de Castilhos, Nova Palma, Quevedos e São Pedro do Sul -, totalizando 14 municípios. Todos os 14 contextos pesquisados possuem CME criado por lei municipal, porém um deles, Ivorá, com CME inativo na ocasião da realização curso em 2014.

As duas conselheiras de Ivorá, após participarem do curso, assim se manifestaram sobre a reativação do conselho de educação de seu município:

As reflexões durante o curso proporcionaram um olhar para o papel e a função do conselho junto ao sistema educacional. Com o curso verificamos que há a necessidade urgente em ativar o conselho municipal de educação, como órgão colaborativo para ações e decisões do processo educacional. (Conselheira B) 
Através do projeto integrador desenvolvido no curso, foram feitas propostas principalmente para a reativação do Conselho e, assim, modificação no mesmo. (Conselheira A)

A compreensão e a produção técnica sobre políticas educativas e gestão pública municipal se constitui democrática quando os sujeitos e os contextos que compõem as redes e sistemas de ensino ampliam seus horizontes, qualificam suas práticas e se reorganizam para qualificar seus espaços de trabalho alinhados ao paradigma educacional vigente.

Em estudo comparativo acerca das duas primeiras edições do Pró-Conselho/UFSM, produzido para oXIV Congresso Nacional de Educação Comparada, realizado em Madrid, Espanha, em novembro de 2014, constatou-se um percentual por períodos relativo a existência dos SME no Estado do RS, considerando a data de criação do Sistema Municipal de Ensino.

Gráfico 1 -

Período de criação dos SME no RS.

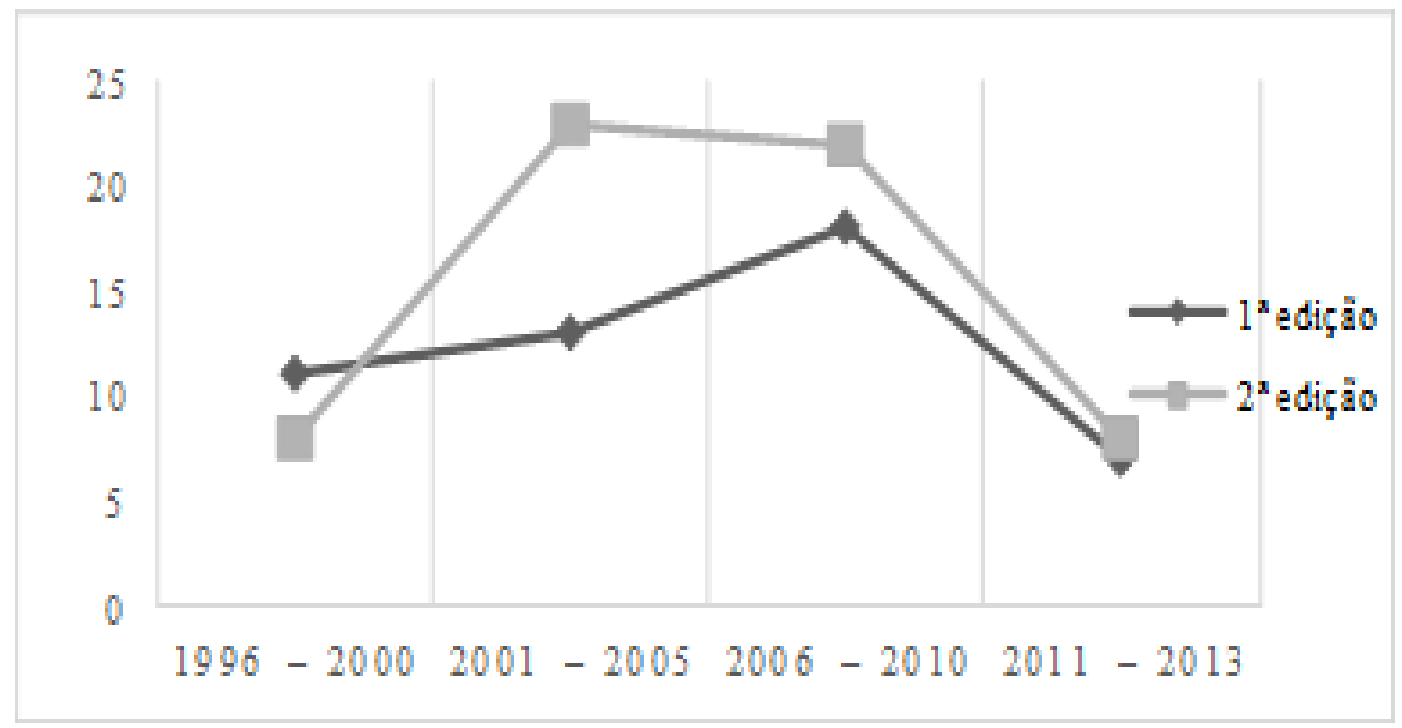

Fonte: Dalla Corte, et al., 2014, p. 11.

A gestão do conselho de educação, na perspectiva da existência do sistema municipal de ensino, amplia a autonomia e a responsabilidade desse órgão colegiado. É lógico que não se pode afirmar que em casos de municípios que possuem SME a autonomia e os mecanismos de gestão junto a educação local se efetivem propriamente dito, essa é uma questão que perpassa pela compreensão e apropriação das políticas públicas pelos conselheiros de educação e, sobretudo, pela luta e conquista de espaços educacionais mais democráticos.

Também no mesmo estudo foram agrupados municípios que participaram das $1^{\underline{a}} \mathrm{e}$ $2^{\mathrm{a}}$ edições do Pró-Conselho no RS, de acordo com a data de criação do CME e, nesse sentido, constatou-se o que segue. 
Gráfico 2 -

Período de criação dos CME no RS.

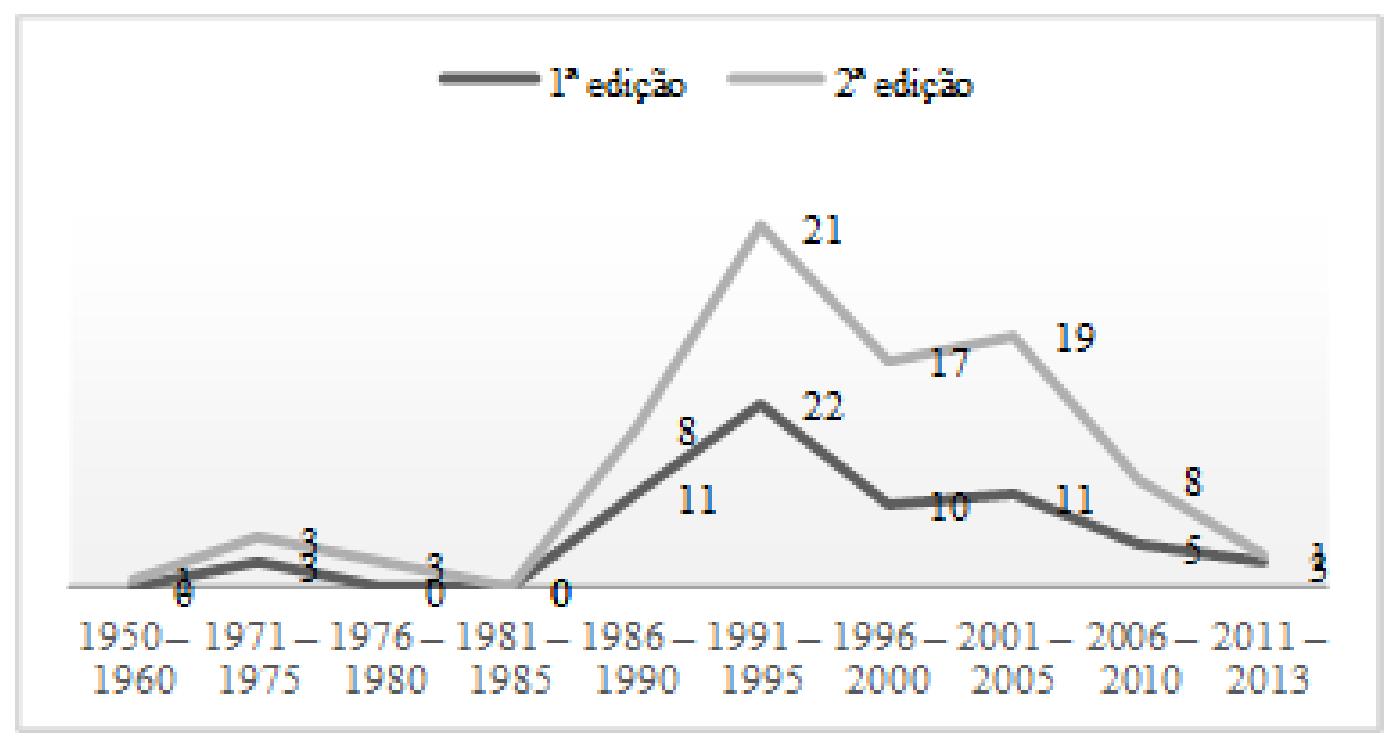

Fonte: Dalla Corte et al., 2014, p. 11.

Com base nos dados do gráfico 2 constata-se que a intensificação da criação de conselhos municipais de educação se concretizou de maneira significativa após a aprovação da Constituição Federal de 1988 e, também, possui intima relação com a aprovação da LDB de 1996. Peroni (2008) faz alusão ao surgimento dos conselhos municipais de educação no período após a LDB/96, inferindo o CME como mecanismo de descentralização das políticas públicas. Para tanto, a criação de conselhos de educação estaria relacionada à função de controle social, de participação e de representatividade da sociedade na proposição e promoção das políticas públicas complementares e personificadas à educação municipal.

Com base em dados subjacentes as respostas ao questionário online, sublinha-se impactos do curso na formação e atuação dos conselheiros de educação dos municípios da Amcentro/RS. Percepções e concepções como a dos conselheiros abaixo, perpassam pela análise do trabalho junto ao curso e pela formação desenvolvida a qual desencadeia novos olhares e reflexão acerca das políticas públicas e processos de gestão educacional.

Quando questionados sobre se os estudos e discussões no Pró-Conselho/UFSM proporcionaram ou não mudanças e melhorias na formação e no trabalho desenvolvido junto ao CME e educação municipal, $100 \%$ dos pesquisados sinalizaram que o curso é importante e mobilizador de produção do conhecimento e de novas práticas sociais e educacionais no contexto dos seus municípios, em especial do CME. Essa perspectiva verifica-se nas manifestações das conselheiras:

Sim. Com o conhecimento e discussões realizadas no curso me sinto mais capacitada e com argumentos legais para exigir e agir no CME. Credibilidade, segurança, fundamentação teórica tão importante para a atuação no Conselho. (Conselheira B - CME Dilermando de Aguiar) 
Certamente, os estudos no Pró-Conselho trazem mudanças e melhorias na minha formação, pois através das várias leituras e discussões, serviram para que eu conhecesse melhor a realidade do meu município a de outros em relação ao CME e, também, para que eu percebesse a importância do trabalho do CME no município e a grande responsabilidade que esse tem dentro da educação do município. As leituras foram fundamentais, a partir delas adquiri novos conhecimento principalmente em relação a leis. Os temas desenvolvidos trouxeram formação para que eu possa realizar um trabalho mais significativo no CME e de mobilização frente a sociedade. (Conselheira A - CME Restinga Seca)

A ampliação e o aprofundamento da capacidade de atuação dos conselheiros de educação é compreendida mediante a articulação entre o exercício das funções subjacentes e a reflexão teórica e política a respeito dos fundamentos de suas atividades. Nesse aspecto, o fortalecimento e a atuação qualificada dos conselhos municipais, como efetivos órgãos de sistema de ensino, poderá se concretizar no seio da política de democratização da gestão educacional.

Além disso, os conselheiros sinalizam que o curso propiciou o conhecimento da realidade de outros CMEs e, nesse sentido, a apropriação de informações acerca de como estão constituídos tais órgãos colegiados, as situações administrativas, pedagógicas e financeiras que envolvem cada rede/sistema de ensino, as experiências quanto aos encaminhamentos realizados ou não pelos CMEs:

A partir de agora, com certeza, poderei fazer um trabalho mais seguro no Conselho, bem como dividir esses conhecimentos com os demais conselheiros para além de meu município. A troca de informações com os conselheiros de outros CMEs foi muito importante, pois fez repensar o trabalho que precisa ser coletivo num CME. (Conselheira B - CME São Sepé)

No contexto da gestão educacional e escolar os sujeitos partícipes têm muitas funções e respectivas atribuições. Sabe-se que a jornada de trabalho, da maioria dos envolvidos é extensa e, para tanto, verificou-se que os cursistas do Pró-Conselho precisaram reorganizar seus horários para acessar e participar no ambiente do curso, estabelecer interatividade e interação, bem como proceder as atividades de estudo e elaboração das tarefas subjacentes. A conselheira B do CME São Sepé sinalizou que

os estudos no Pró-Conselho estão ajudando muito na minha ação no CME, pois 'obrigaram a achar mais tempo para estudar' e assim manter-me atualizada sobre os assuntos pertinentes à educação. Nas reuniões do CME estudamos, mas é verdade que o tempo é pouco.

$\mathrm{Na}$ mesma linha de pensamento constata-se a posição da conselheira $\mathrm{A}$ do $\mathrm{CME}$ Júlio de Castilhos: "Sim maior aprendizagem, mesmo não disponibilizando de horas para estudar e por isso precisando rever meus tempos". Verifica-se que mesmo constituindo-se um curso a distância, o Pró-Conselho requer que os partícipes delimitem e reorganizem seus tempos e espaços de estudo e produção do conhecimento. Essa perspectiva vai depender do interesse, compromisso e proatividade de cada um. 
Os conselhos municipais de educação são mecanismos indispensáveis e necessários para dar consecução à gestão democrática na educação básica, por isso são pensados estrategicamente pela Secretaria de Educação Básica em seus processos formativos. Faz-se necessário aos que atuam junto a esses órgãos colegiados que estabeleçam, fundamentadamente, processos dialógicos com os sujeitos e as demandas sociais e, sobretudo, o estabelecimento de prioridades, metas e estratégias educacionais de seus municípios, no sentido de reconstruir de maneira responsável e participativa políticas públicas para as etapas e as modalidades da educação básica. Considera-se o posicionamento de alguns conselheiros a esta perspectiva:

Todos os textos do curso estão sendo impressos para que os conselheiros possam apropriar-se, usando-os sempre durante o trabalho junto ao CME. (Conselheira A - CME Formigueiro)

Sim, eu faço parte da Secretaria de Educação e do Conselho, estou passando tudo que aprendo aos membros do conselho e aos colegas da secretaria. (Conselheira A - CME Nova Palma)

As leituras e estudos no curso estão ajudando nas mudanças no trabalho desenvolvido junto ao conselho, principalmente os materiais disponibilizados levo nas reuniões dos conselheiros para estudá-los. (Conselheira A - CME São Vicente do Sul)

A formação proposta pelo Pró-Conselho, entendido e executado como política pública, se redimensiona quando tais partícipes do curso constituem-se como multiplicadores dos estudos e discussões em seus contextos de atuação ampliando, efetivamente, o processo político-pedagógico do curso ao encontro das necessidades sociais e educacionais dos respectivos municípios em suas conexões com a compreensão das políticas públicas e suas inter-relações com os processos de gestão educacional e escolar. Os CMEs têm o desafio e compromisso de desempenhar significativo papel na consolidação dos Sistemas de Ensino. Nesse sentido, estes órgãos colegiados podem se constituir efetivamente locus para encaminhamento de discussões indispensáveis voltadas à organização, manutenção e desenvolvimento do ensino, assim como à proposição de políticas públicas para a educação municipal.

Bordignon (2009) destaca que entre as temáticas que os conselhos de educação podem deliberar ou realizar consultas, destacam-se: normativa - quanto a regulamentação do funcionamento do Sistema de Ensino e elaboração do seu regimento; interpretativa diz respeito à interpretação e gestão de conflitos e dúvidas; credencialista - se refere a aprovação, credenciamento e autorização das instituições de ensino e dos cursos e, dependendo, também, aprovação de projeto político-pedagógico e regimento; recursal relacionada a resolução de conflitos; ouvidora - condição de ouvir os cidadãos e instituições com vistas aos direitos educacionais. Assim, sublinha-se pelas falas dos pesquisados que eles passaram a compreender melhor ou ampliaram as funções e atribuições desse órgão colegiado que é o conselho de Educação em um município que possui SME: 
Especialmente no que estudei sobre as funções dos conselheiros e ao Regime de Colaboração no Brasil, descobri muitos detalhes sobre os princípios de gestão democrática e relações com as ações do CME na gestão municipal. (Conselheira B - CME São Sepé)

É muito importante entender melhor o papel do CME sobre as questões educacionais municipais e buscar a valorização, o respeito, a autonomia e o papel de mobilizador que o CME precisa ter na educação municipal. Investir em mais segurança e conhecimento em relação às legislações e maior empoderamento e discernimento nas decisões que deverão ser tomadas nos dá força para lutar e buscar a melhoria da educação municipal. (Conselheira A - CME Dilermando de Aguiar)

Nessa lógica, constata-se que o conselho de educação precisa se constituir num mecanismo de mobilização, controle e mediação entre a sociedade e o poder público, 0 que, de certa forma, ampliam-se as possibilidades de representatividade, acompanhamento, assessoramento, interlocução e divulgação das decisões, deliberações compartilhadas e espaços de articulação, negociação e democratização das demandas sociais e educacionais no município. Considerando a visão ampliada das funções e atribuições do CME pelos conselheiros pesquisados, identificou-se no posicionamento dos pesquisados:

Sim. Os estudos oferecidos pelos módulos proporcionaram conhecimentos sobre a importância do CME e sua atuação frente ao sistema educacional. (Conselheira B - CME Quevedos)

Proporciona uma reflexão mais aprofundada acerca das legislações educacionais vigentes e pertinentes, bem como a produção do conhecimento e de políticas educativas no sistema de ensino. (Conselheira A - CME Santa Maria)

O princípio de gestão democrática está expresso na Constituição Federal (Brasil, 1988) e na Lei de Diretrizes e Bases da Educação Nacional (Brasil, 1996). Nesse sentido, configura-se outro modo de organização dos sistemas de ensino e, com isso, o município, como ente federado, assumiu relevante função educacional, já que pode criar o seu sistema de ensino. Nessa conjuntura de cooperação técnica entre os entes federados, os CMEs configuram-se como importantes instâncias colegiadas de representatividade social e efetivação dos princípios que balizam a gestão democrática dos municípios para produzirem e gestarem suas políticas educacionais (Bordignon; Pereira, 2008). Tais percepções sinalizadas acima pelos conselheiros repercutem nessa visão e concepção ampliada de sistema de ensino, uma vez que no curso são trabalhados conhecimentos sobre o que, a importância e a atuação de um conselho de educação em município que possui sistema municipal de ensino ou não e inter-relações com as políticas públicas nacionais para a educação básica, bem como a relação delas com mecanismos multilaterais. Certamente, as funções e atribuições do CME ficam restritas em espaços municipais que não constituíram SME.

Quando questionados acerca das percepções e aprendizagens sobre as tecnologias digitais/educacionais, a partir da utilização do ambiente Moodle-conselheiros do PróConselho, os conselheiros pontuaram algumas questões importantes. 
Quadro 1 -

Percepções e aprendizagens sobre as tecnologias digitais/educacionais na $2^{\mathfrak{a}}$ edição do Pró-Conselho/UFSM.

\begin{tabular}{|l|l|}
\hline $\begin{array}{l}\text { Aprendi muito com estas tecnologias de aprendizagem, salientando a } \\
\text { importância da troca de experiências com outros municípios e suas } \\
\text { realidades, às vezes muito parecidas e outras bem distante da nossa } \\
\text { realidade. }\end{array}$ & Mata \\
\hline É a primeira vez que participo e achei o máximo, pois é muito & \\
eficiente e prático, a gente organiza os estudos dentro do prazo & \\
estipulado no módulo, não acontece as interferências externas como & Restinga Seca \\
na aula presencial, as orientações da tutora são fundamentais e nos & \\
dão muita segurança, as discussões contribuem muito para a & \\
aprendizagem, etc. & \\
\hline As tecnologias de informação e comunicação, tem um papel & \\
importante, o de fazer o registro contínuo das interações, produções & \\
e caminhos percorridos, permitindo recuperar instantaneamente a & Santa Maria \\
memória de qualquer etapa do processo, analisá-la, realizar tantas & \\
atualizações quantas forem necessárias, bem como flexibilizar o & \\
acesso ao conhecimento aos diferentes contextos geográficos. & \\
\hline Aprendi muito sobre as tecnologia digitais neste curso. Não me & \\
relacionava muito bem com elas; no início fiquei muito temerosa em & \\
lidar no ambiente moodle, mas aos poucos com as ótimas & São Sepé \\
orientações do primeiro encontro presencial [...] consegui perder o \\
medo e fazer com sucesso as minhas atividades on-line. Considero \\
que me saí muito bem na minha primeira experiência em EAD. \\
\hline
\end{tabular}
Fonte: banco de dados do Obeduc/Elos/UFSM, 2014.

Os processos formativos vivenciados pelos cursistas, tendo por base subsídios teóricos e legais acerca da conjuntura das políticas públicas e processos de gestão subjacentes as instâncias deliberativas e consultivas dos CME, bem como as discussões, reflexões e análises dos contextos de atuação dos conselheiros, se configuram na dinâmica de redes de aprendizagem. Tais formativos, sejam eles pelos encontros presenciais ou pela interatividade/interação no Moodle, sublinham a reconstrução do conhecimento e a produção de saberes e fazeres dos envolvidos nos conselhos municipais de educação e nas secretarias municipais de educação:

Os conselheiros de educação, compreendendo e dominando aspectos relacionados ao avanço tecnológico e à inserção das tecnologias digitais (TDs) no cotidiano das Redes e dos Sistemas de Ensino poderão tomar decisões, fazer escolhas e realizar encaminhamentos políticopedagógicos, presencial e a distância, os quais podem ser otimizados e configurados de maneira mais proativa, participativa, contextualizada e atualizada. (Dalla Corte et al, 2014, p. 169)

Nessa lógica, compreende-se que além do conselho de educação se constituir um mecanismo de interlocução entre a sociedade e o poder público, o reconhecimento, o domínio e a utilização das tecnologias digitais/educacionais, pelos sujeitos que lá atuam, qualifica a comunicação, a produção e a gestão em suas relações com o cotidiano das políticas públicas educacionais. A produção técnica na seara das políticas educativas e da gestão pública municipal pode se constituir democrática, na medida em que os sujeitos se 
empoderam e otimizam de novas formas de relacionar o conhecimento, e de relacionamento com o conhecimento, bem como estabelecem processos comunicacionais e de cultura organizacional que transcendem os tempos e espaços analógicos.

\section{Conclusões}

Neste texto põem-se em destaque e discussão o Pró-Conselho/UFSM, enquanto espaço-tempo formativo e como lócus de pesquisa de um Observatório de Educação da Capes, daí suas interlocuções com a produção do conhecimento no âmbito das políticas públicas e da gestão da educação básica.

Assim sendo e, tendo por base o objetivo de analisar os impactos da formação continuada desenvolvida no âmbito da $2^{\text {a }}$ edição Pró-Conselho/UFSM da atuação dos conselheiros junto aos conselhos municipais de educação na região de abrangência da Associação dos Municípios do Centro do Estado do Rio Grande do Sul, apresentam-se como principais impactos do curso na formação e atuação dos conselheiros de educação os seguintes:

a) ampliação e aprofundamento da capacidade de atuação dos conselheiros possibilitando a articulação entre o exercício da função e a reflexão teórica e política a respeito dos fundamentos dessa atividade;

b) fortalecimento dos conselhos municipais de educação como efetivos órgãos de sistema de ensino;

c) reativação ou rearticulação de conselhos municipais de educação que estavam inativos na região central do Estado do Rio Grande do Sul;

d) sensibilização e construção do conhecimento na área das políticas públicas e gestão educacional, relacionando as funções e atribuições dos CMEs à existência de sistemas de ensino, bem como a sua democratização;

e) reorganização dos tempos de estudo e investimento nos processos de autoformação pelos conselheiros, inclusive como multiplicadores dos conhecimentos produzidos e discutidos no curso junto aos seus pares;

f) entendimento do paradigma educacional que norteia uma prática pedagógica com o uso das tecnologias digitais/educacionais;

g) qualificação do conhecimento dos cursistas quanto a inserção e utilização das tecnologias digitais, em especial o ambiente virtual de aprendizagem, com todas as suas ferramentas de comunicação, interação e seus recursos didático-pedagógicos;

h) estabelecimento de uma rede compartilhada virtual entre conselheiros municipais de educação e técnicos de secretarias municipais de educação, entre outros, para discussão e reconstrução do conhecimento acerca das políticas públicas e gestão da educação básica.

Tais impactos sinalizados pelos conselheiros reverberam na necessária compreensão e a realização de um trabalho educativo coletivo, compartilhado, pautado em autonomia, descentralização do poder e transparência nas instâncias educacionais municipais. Esses princípios subsidiam e fundamentam a gestão da educação básica que se quer e se normatiza democrática no país, desde os preceitos da CF/88 e da LDBN/96. Sobretudo, as políticas públicas educacionais precisam ser delineadas, articuladas e 
implantadas na lógica das interdependência e, portanto, requerem a instauração efetiva de sistemas de ensino mediatizados pelo trabalho comprometido e competente, entre outros atores, dos Conselhos Municipais de Educação.

Ao utilizar o ambiente virtual como mecanismo de compartilhamento de informações e discussões de saberes e fazeres, assim como na produção do conhecimento, o conselheiro de educação rompe barreiras analógicas e passa a redimensionar sua maneira de estudar e de trabalhar, avançando da lógica individual para a lógica coletiva.

Compreende-se, portanto, que as ações extensionistas realizadas pela Universidade Federal de Santa Maria, a partir da implementação do Pró-Conselho no Rio Grande do Sul, contribuem, segundo os pesquisados, para propiciar espaços para a reflexão conjunta, de maneira que tais sujeitos possam resignificar seus saberes e fazeres acerca das políticas públicas e processos de gestão educacional, bem como produzir conhecimentos significativos e fundamentados para sua atuação nos conselhos municipais de educação.

\section{Referências}

BOGDAN, Roberto C.; BIKKLEN, Sari Knopp. Investigação qualitativa em educação. Porto: Porto, 1994.

BORDIGNON, Genuíno. Gestão da educação no município: sistema, conselho e plano. São Paulo: Instituto Paulo Freire, 2009.

BORDIGNON, Genuíno. Perfil dos conselhos municipais de educação. Brasília: MEC, 2008.

BRASIL. Constituição da República Federativa do Brasil de 1988. Disponível em <http://www.planalto.gov.br>. Acesso em 10 nov. 2014.

BRASIL. Lei n. 13.005, de 25 de junho de 2014. Estabelece o Plano Nacional de Educação. Diário Oficial da União, Brasília. Disponível em <http://www.planalto.gov.br/ ccivil_03/_Ato2011-2014/2014/Lei/L13005.htm>. Acesso em 14 jun. 2015.

BRASIL. Lei n. 9.394, de 20 de dezembro de 1996. Lei de Diretrizes e Bases da Educação Nacional. Brasília, 1996. Disponível em <www.planalto.gov.br>. Acesso em 18 abr. 2015.

CASTELLS, Manuel. A sociedade em rede. São Paulo: Paz e Terra, 2005.

DALLA CORTE, Marilene Gabriel et. al. A conjuntura dos conselhos municipais de educação do Estado do Rio Grande do Sul - Brasil na perspectiva da educação comparada. CONGRESSO NACIONAL DE EDUCAÇÃO COMPARADA, 14, 2014. Anais ... Madrid: Universidade Autônoma de Madrid, 2014, p. 1-15. Disponível em <http://www.congresoseec2014.org/> Acesso em 10 ago. 2015.

DALLA CORTE, Marilene Gabriel; MELLO, Andrelisa Goulart de. Da conjuntura histórica dos conselhos de educação à abrangência do programa nacional de capacitação de conselheiros municipais de educação. In: DALLA CORTE, Marilene Gabriel (org.). Políticas públicas e conselhos municipais de educação: interlocuções com o PróConselho. São Leopoldo: Oikos, 2015, p. 21-46.

FRIGOTTO, Gaudêncio. Reformas educativas e o retrocesso democrático no Brasil nos anos 90. In: LINHARES, Célia (org). Os professores e a reinvenção da escola. São Paulo: Cortez, 2001, p. 57-80.

GIL, Antonio Carlos. Como elaborar projetos de pesquisa. São Paulo: Atlas, 2004.

\begin{tabular}{|l|l|l|l|l|r|}
\hline Regae: Rev. Gest. Aval. Educ. & Santa Maria & v. 5 & n. 9 & Jan./jun. 2016 & p. 75-92
\end{tabular}


GÓMEZ, Angel Pérez. O pensamento prático do professor: a formação do professor como profissional reflexivo. In: NÓVOA, António (coord.). Os professores e a sua formação. Lisboa: Dom Quixote, 1997, p. 93-114.

INEP. Censo escolar de 2014. Disponível em <http://portal.inep.gov.br/basica-censoescolar-sinopse-sinopse>. Acesso em 14 jun. 2015.

LIBÂNEO, José Carlos; OLIVEIRA, João Ferreira; TOSCHI, Mirza Seabra. Educação escolar: políticas, estrutura e organização. São Paulo: Cortez, 2005.

LÜCK, Heloisa. Concepções e processos democráticos de gestão educacional. Petrópolis: Vozes, 2006.

LÜCK, Heloisa. Gestão educacional: uma questão paradigmática. São Paulo: Vozes, 2007.

MINAYO, Maria Cecília de Souza (org.). Pesquisa social: teoria, método e criatividade. Petrópolis: Vozes, 2004.

MONLEVADE, João Antônio Cabral de. Plano municipal de educação. In: MINISTÉRIO DA EDUCAÇÃO (org.). Conselho municipal e suas articulações com as políticas públicas. Brasília: MEC, 2009, p. 75-94.

PERONI, Vera Maria Vidal. Conselhos municipais em tempos de redefinição do conceito de democracia. In: SOUZA, Donaldo Bello (ed.). Conselhos municipais e controle social da educação: descentralização, participação e cidadania. São Paulo: Xamã, 2008, p. 191209.

TELLES, Rosangela Mendonça. O papel dos conselhos de educação na formação dos sistemas educacionais brasileiros. REUNIÃO ANUAL DA ASSOCIAÇÃO NACIONAL DE PÓS-GRADUAÇÃO E PESQUISA EM EDUCAÇÃO, 24. 2001. Anais ... Caxambu: Anped, 2001.

TRIVIÑOS, Augusto Nivaldo S. Introdução à pesquisa em ciências sociais: a pesquisa qualitativa em educação. São Paulo: Atlas, 2008.

YIN, Richard. Estudo de caso: planejamento e métodos. Porto Alegre: Bookman, 2005.

Marilene Gabriel Dalla Corte é doutora pela Pontifícia Universidade Católica do Rio Grande do Sul e professora na Universidade Federal de Santa Maria. Coordenadora Geral do Pró-Conselho - UFSM, pesquisadora junto ao programa Observatório da Educação da Coordenação de Aperfeiçoamento de Nível Superior - Capes.

Endereço: Avenida Roraima, 1000 - Centro de Educação - 97015-970 - Santa Maria - RS - Brasil.

E-mail: marilenedallacorte@gmail.com.

Andrelisa Goulart de Mello é mestre em Educação pela Universidade Federal de Santa Maria. Doutoranda em Educação do Programa de Pós-Graduação do Centro de Educação da mesma instituição. Professora da Educação Básica no Colégio Sant'Anna em Santa Maria-RS.

Endereço: Avenida Roraima, 1000 - Centro de Educação - 97015-970 - Santa Maria - RS - Brasil.

E-mail: andrelaizes@gmail.com. 
Marina Lara Silva dos Santos Teixeira é estudante do Curso de Matemática Licenciatura pela Universidade Federal de Santa Maria.

Endereço: Avenida Roraima, 1000 - Centro de Educação - 97015-970 - Santa Maria - RS - Brasil.

E-mail: marinalaraobeduc@gmail.com.

Francine Mendonça da Silva é licenciada em Pedagogia pelo Centro Universitário Franciscano, especialista em Gestão Educacional pela Universidade Federal de Santa Maria e professora formadora e apoio administrativo do Curso de Formação Continuada de Conselheiros Municipais (Pró-Conselho/UFSM).

Endereço: Avenida Roraima, 1000 - Centro de Educação - 97015-970 - Santa Maria - RS - Brasil.

E-mail: cinebsb@gmail.com.

Recebido em 14 de novembro de 2015.

Aceito em 9 de dezembro de 2015. 